\title{
IbN Gabirol e a Origem do Mundo: Apontamentos sobre a Questão da Unidade
}

\author{
Cecilia Cintra Cavaleiro de Macedo ${ }^{I}$
}

\begin{abstract}
RESUMO: Ibn Gabirol apresenta, em sua obra Fons Vitae, um modelo metafísico baseado no hilemorfismo universal, ou seja, na presença de matéria e de forma em todos os seres, tanto corpóreos quanto espirituais. Embora considerado um autor neoplatônico, Ibn Gabirol não explicita propriamente uma henologia, mas parte das realidades sensíveis e corpóreas em direção às mais sutis. Este artigo pretende inverter essa apresentação do autor, buscando redesenhar sua metafísica a partir da Essência Primeira até o fim da criação. Para tanto, o ponto específico analisado, ainda que de modo incipiente, é a questão da unidade e seu qualificativo uno/una, tanto na atribuição que ele faz em seu modelo ontológico, quanto nos seus aspectos lógicos.
\end{abstract}

PALAVRAS-CHAVE: Uno. Unidade. Ibn Gabirol. Neoplatonismo. Hilemorfismo Universal. Matéria.

Apesar de ter sido considerado um dos autores mais lidos pelos filósofos latinos, durante o século treze, Ibn Gabirol, ou melhor, Avicebron ou Avencebrol, como ficou conhecido na Escolástica, é ainda um autor pouco estudado. As brumas que desceram sobre sua verdadeira identidade e confissão religiosa, até 1845 , quando Salomon Munk o identificou como o importante poeta judeu espanhol, contribuíram para isso. No âmbito do Cristianismo, outro fator que conduziu ao abandono do estudo de sua obra pode ter sido a importância central que a obra de Tomás de Aquino adquiriu para os estudiosos de Filosofia Medieval, uma vez que o dominicano discorda veementemente das teses centrais propostas por este autor ${ }^{2}$. Em seus escritos,

\footnotetext{
${ }^{1}$ Departamento de Filosofia - Unifesp. E-mail: cavaleirodmacedo@uol.com.br.

${ }^{2}$ Tomás de Aquino dedica-se à refutação da obra de Ibn Gabirol, retornando umas quinze vezes, em $D e$ Ente et Essentia, De spiritualibus creaturis, De substantiis separatis, Quodlibeta etc. Para todos os trechos em que S. Tomás critica as ideias de Ibn Gabirol, ver BRUNNER, 1965, p. 36.
} 
reforça a inadmissibilidade da doutrina hilemórfica e o erro de Gabirol em relação às questôes das quais veementemente discordou. Ainda que na escola franciscana sua doutrina tenha sido recebida com bons olhos, seu nome foi apagado ao longo das geraçôes, tendo sido substituído pelo dos pensadores cristãos já anteriormente influenciados por suas ideias.

Já no âmbito do judaísmo, a partir do século XII, o fator preponderante foi a centralidade de Maimônides com a "novidade" de uma orientação mais aristotélica e o consequente debate sobre as obras desse autor, que dividiu os pensadores judeus entre "racionalistas" e "místicos". Esse processo favoreceu, por um lado, não apenas a radicalização da posição do próprio Maimônides por seus seguidores, como também a popularização da Kabbalah, de outro, legando os pensadores mais declaradamente neoplatônicos anteriores, especialmente Isaac Israeli e Ibn Gabirol, ao esquecimento. É público que Maimônides desconsiderava a filosofia platônica em si mesma ${ }^{3}$, bem como chegava a desprezar seu antecessor Israeli, descrevendo-o como um grande médico, mas que não se poderia chamar de filósofo. Quanto a Ibn Gabirol, que, por sua vez, seguia certas linhas mestras já antecipadas por Israeli ${ }^{4}$, jamais foi referido pelo RaMBaM, o que conduz à interpretação de que aquele não tenha sequer lido suas obras.

É certo que, no seio da Kabbalah, em suas variantes mais filosóficas, as ideias de Gabirol exerceram forte influência, ainda que tenha sido pouco citado diretamente 5 . Ademais, seu pensamento alcança até o Renascimento, com Leão Hebreu (Yehuda Abravanel) ${ }^{6}$, e mais além, mas podemos dizer que já chega ao Renascimento e à Modernidade, de certo modo, reinterpretado e rotulado, uma vez que lido junto aos comentários da Escolástica Cristã. Logo da identificação de sua obra Fons Vitae por Salomon Munk, houve um auge de interesse dos estudiosos judeus em sua obra, especialmente por esse episódio estar situado no período da Haskalah, ou Wissenchaft judaica. Mas, uma vez que

\footnotetext{
${ }^{3}$ Toda a discussão desenvolvida por Maimônides no Guia dos Perplexos é dirigida pela filosofia de Aristóteles, já que, para ele, esta seria a "[...] única merecedora de consideração" (MAIMÔNIDES, 1956, II, 14).

${ }^{4}$ Como a própria questâo da matéria e da forma primeiras. Ver ALTMANN, A. First Matter and first form (Wisdom) - Intellect. In: ALTMANN, STERN, 1958, p. 159-164.

5 "Os cabalistas podem perfeitamente ter conferido pseudônimos aos livros árabes dos quais nós já falamos, assim como ao livro de Ibn Gabirol, e este último talvez deva ser considerado como um dos fundadores da Kabbalah especulativa” (MUNK, 1927, p. 283).

${ }^{6}$ Leão Hebreu se refere ao filósofo como "[...] il nostro Albenzubron", o que sugere que este não desconhecia a identidade judaica do filósofo (VILA-CHÃ, João S. J. In: LEÃO HEBREU, 2001), p. 43.
} 
não é um pensador que pode ser catalogado apropriadamente como inserido na "Filosofia do Judaísmo ${ }^{7}$ ", porque sua temática não procede das questóes religiosas, logo foi abandonado, passando a ser objeto de interesse quase somente entre os estudiosos das influências sofridas pela Escolástica Cristã e por seu interesse histórico na composição das ideias de pensadores ibéricos ulteriores. Todavia, esse relativo abandono não cancela sua importância na história do pensamento filosófico medieval, importância esta atestada pela influência exercida na história do pensamento e das ideias filosóficas.

Infelizmente, a única obra de metafísica atribuída a Ibn Gabirol que chegou até nossos dias foi precisamente o Fons Vitae $e^{8}$, ainda que se acredite que tenha escrito provavelmente mais dois livros sobre o assunto ou, no mínimo, mais uma obra sobre a Vontade 9 . O Fons Vitae foi originariamente redigido em árabe, mas o texto foi perdido e só nos chegaram duas fontes: uma tradução latina ${ }^{10}$, que se acredita ser completa e uma pequena coletânea de passagens em hebraico, na qual somente as passagens mais importantes são reproduzidas, denominada Likkudim Min Sefer Mekhor Haim ${ }^{11}$. Portanto, qualquer trabalho sobre o texto deve ser necessariamente apoiado nesta tradução latina e requer do estudioso um esforço adicional em tentar imaginar, através dos equivalentes usuais na tradição escolástica, os conceitos originais em árabe que provavelmente teriam sido aqueles utilizados pelo autor.

\footnotetext{
7 "Desde a antiguidade, a filosofia judaica foi essencialmente uma filosofia do judaísmo. Mesmo na Idade Média - que conheceu algo como uma total e abrangente cultura baseada na religiâo - raras vezes ela transcendeu seu centro religioso" (GUTTMANN, 2003, p. 28).

${ }^{8}$ Todas as citaçôes do texto do Fons Vitae que figuram neste artigo são originárias de tradução nossa do texto latino, a qual pretendemos que seja publicada como um todo, em breve. As referências ao texto aparecerão entre parênteses, abreviadas como F.V., seguidas do número do tratado correspondente em algarismos romanos e do número do capítulo, como a seguir: (F.V., V, 40).

9 "E, para conhecer as açôes da Sabedoria e suas obras, os fins de suas disposições e a igualdade em seus motivos e em suas impressóes, para conhecer o descanso de seu movimento, o estado de sua ação, os lugares de sua manifestação e ocultação, para conhecer de que natureza é a forma que dela procede, antes e depois que se manifeste, e para conhecer o restante que disso se segue e do qual nós ainda não nos ocupamos, nesta discussão. Já tenho dispostos os discursos acerca de tudo isso no livro que trata do conhecimento da Vontade, e esse livro se chama Origo largitatis et causa essendi, que deve ser lido depois deste. Por ele conhecerás a verdade da criação, a respeito da qual me perguntaste”. (F.V., V, 40).

${ }^{10}$ Traduzido por Juan Hispano e Domingo Gundissalino e publicado por Baeumker: AVENCEBROLIS (IBN GABIROL) Fons vitae/ex Arabico in Latinum translatum ab Iohanne Hispano et Dominico Gundissalino; ex codicis Parisinis, Amploniano, Columbino primum edidit Clemens Baeumker. Münster: Aschendorff, 1895.

${ }^{11}$ Seleção de passagens organizada por Shem Tov Ibn Falaqera e publicada por Munk, no seu livro Mélanges de Philosophie Juïve et Arabe. Esse texto não segue a organização original do texto em forma de diálogos, tendo suprimido as perguntas dos discípulos e resumido as respostas do mestre.
} 
A obra A Fonte da Vida é dedicada à demonstração da teoria fundamental de Ibn Gabirol: o hilemorfismo universal. Para esse autor, toda a realidade criada é composta por matéria e forma, desde o primeiro ser até o último, o que quer dizer: desde os espirituais mais simples e sutis até os corpos sensíveis particulares. As únicas exceçóes ao modelo são precisamente aquelas incriadas, ou seja, as que estão fora dessa composição: somente Deus mesmo, denominado por ele, na maior parte das vezes, Essência Primeira, e Sua Vontade, concebida enquanto uma propriedade da Essência que age como intermediário criador. A obra é composta por cinco "livros" ou tratados, cada um deles dedicado à demonstraçáo da matéria e da forma em algum nível de corporeidade ou espiritualidade, à exceção do tratado terceiro, no qual pretende demonstrar a existência mesma desses intermediários entre Deus e a corporeidade, chamados por ele de substâncias simples. Note-se que, em virtude de tudo ser composto por matéria e forma, a tudo ele denomina substância, independentemente de seu grau de corporeidade ou materialidade, visto que concorda com as demais na própria substancialidade.

O livro primeiro apresenta explicaçôes preliminares sobre a importância do estudo e seu objetivo, bem como discorre sobre os saberes necessários a essa investigação que, a seu ver, são a lógica e o conhecimento básico sobre a alma. Além disso, aborda o que se deve estabelecer previamente para a determinaçáo da matéria e da forma universais e para a determinação da matéria e da forma nas substâncias compostas. O livro segundo trata particularmente daquilo que o autor denomina a substância que suporta a corporeidade do mundo, que é a substância universal da matéria revestida de forma corpórea. No livro terceiro, estabelece a existência das substâncias simples, que seriam as intermediárias entre o primeiro agente ou eficiente, ou seja, no caso específico da criaçáo, entre Deus/Essência Primeira e Sua Vontade enquanto potência criadora e o mundo sensível e corpóreo. No livro quarto, pretende demonstrar que essas substâncias também são compostas de matéria e de forma, enquanto no livro quinto trata da matéria universal e da forma universal, das quais todo o mundo sensível e inteligível é composto, e da relação daquelas com a Vontade e com Deus.

Como podemos notar, apesar de seu modelo metafísico geral poder ser associado ao Neoplatonismo, uma vez que se estrutura sobre uma sequência de emanaçôes sucessivas a partir de um princípio uno, Gabirol não faz exatamente uma henologia, visto que não discorre diretamente sobre o modo de processão das realidades com base nesse uno. Talvez esta tenha sido sua intenção nos 
demais livros, aos quais jamais tivemos acesso. Seu caminho no Fons Vitae é inverso, lembrando mais uma ontologia, no sentido aristotélico, porque ele parte da substância mais baixa, sensível e manifesta, a qual ele denomina substância que sustenta as categorias, e vai subindo em direção às realidades mais simples e espirituais ${ }^{12}$. Temas como a própria Vontade Criadora não são muito explorados em sua obra, assim como alusôes sobre a relação desta com o próprio Deus aparecem em passagens muito breves ao final do texto, sem fornecer grandes explicaçóes. Portanto, para falarmos da origem do universo, somos obrigados a inverter o próprio caminho do autor, reconstruindo aquilo que, na própria terminologia de Ibn Gabirol, seria o fluxo ${ }^{13}$ a partir do Uno/ Essência Primeira, e não, como ele mesmo faz, a caracterização das realidades dele defluídas.

Vale ressaltar que muitos estudiosos tentaram conectar o pensamento de Gabirol diretamente ao de Plotino. Ao não encontrarem as equivalências perfeitas, alguns deles concluíram pela contradição ou inconsistência da estrutura metafísica exposta na Fonte da Vida. Mas, há que lembrar que a influência neoplatônica nos pensadores judeus medievais não se resumiu a Plotino. Além do conjunto que ficou conhecido como Teologia de Aristóteles, o qual congrega extratos das Enéadas IV, V e VI de Plotino, temos que considerar o panorama de textos neoplatônicos disponíveis da época, como as influências importantes já destacadas dos seguintes textos: os Elementos de Teologia, de Proclo, matriz do texto árabe Kalam fi mahd al-khair (Liber de Causis para os latinos), o pseudoepigráfico denominado por Stern ${ }^{14}$ Neoplatônico de Ibn Hasday, e o lendário Livro das cinco substâncias, atribuído a Empédocles e

\footnotetext{
12 "Posto que temos intenção de nos elevarmos do mais ínfimo extremo daquilo que existe até o extremo superior, e como todas as coisas que possuem o ser no extremo inferior são provenientes do extremo mais elevado: entáo, cada coisa que encontremos no extremo inferior tomamos como regra para a designação daquilo que está no extremo superior, porque o inferior é exemplo do superior, posto que os que provêm de outros são imagens daquilo do qual provêm. Por isso, porque o inferior descende a partir do superior, é necessário que seja exemplo do superior. E apontaremos posteriormente, nesta investigação, que o inferior descende do superior. E se for conforme dissemos, e conhecermos o termo conveniente de um e outro extremo, entáo será certo o conhecimento do oculto pelo manifesto" (F.V.,II, 7).

${ }^{13}$ Esta é a terminologia dominante na obra, ao se tratar da relação de procedência dos seres criados (fluxo e todas as suas derivaçóes: influxo, defluxo, efluxo etc.), apesar de, em algumas passagens, a tradução latina utilizar outros termos. Essa terminologia parece estar plenamente de acordo com a imagem da Fonte da vida e com a analogia da água que flui a partir desta fonte, desde sua condição mais límpida e livre de impurezas.
}

${ }^{14}$ Ver STERN, 1960-1961. 
apontado por muitos como influência fundamental em Ibn Gabirol ${ }^{15}$. Cremos que o estudo mais detalhado de outras influências neoplatônicas, bem como da especulação interna ao judaísmo, pode desfazer a estranheza inicial e a imagem, a nosso ver precipitada, de inconsistência de seu modelo.

Esse caminho traçado por Gabirol nos conduz a outra questão associada - pergunta natural para um neoplatônico judeu - que consiste na indagação sobre o significado de criação para o autor e seus limites. Embora não seja o tema central deste texto, a questão não pode ser simplesmente desconsiderada, uma vez que constitui a tessitura sobre a qual se erige sua estrutura metafísica: seu modo particular de compatibilização entre seu pano de fundo religioso original e o modelo neoplatônico de emanaçóes sucessivas. Ou seja, a compatibilização entre a doutrina judaica ortodoxa da Criação dos seres como tais, em seis dias e a partir do nada, derivada da interpretação literal do Gênesis, e a proposta neoplatônica de origem de tudo a partir de um Uno superabundante que transborda, conferindo, portanto, algo de sua própria essência a todo o universo existente.

Invertendo assim o caminho percorrido por Gabirol, isto é, conforme ele mesmo nos diz, abandonando o caminho do conhecimento - que parte do mais manifesto em direção ao mais oculto - e seguindo para a descrição do caminho do $\operatorname{ser}^{16}$, que é necessariamente inverso, encontramos a seguinte estrutura. Há, para ele, um Deus absolutamente transcendente, ao qual ele faz a maior parte das referências no texto como Essência Primeira ${ }^{17}$. Pelos nomes e qualificativos atribuídos a Deus, se assim podemos chamar, já podemos

\footnotetext{
${ }^{15}$ Essa possibilidade foi acolhida fervorosamente por Munk e Asín Palácios. Após a publicação do texto por David Kaufmann, em 1899, alguns estudiosos entenderam que Gabirol coloca "[...] a matéria espiritual como a primeira das cinco substâncias" (RUDAWSKI, 2003, p. 150), vinculando o pensamento do autor a essa fonte, embora isso seja bastante discutível, como comenta Guttmann. Nesse caso, a matéria é apenas o primeiro estádio na série de emanaçōes das quais todas as coisas derivaram. A noçẫo característica de Gabirol é que as coisas se compóem de matéria-prima universal e de forma-prima universal, o que vem a ser completamente diferente (GUTTMANN, 2003, p. 116, nota 32). A própria questão da importância do pseudo-Empédocles como fonte confiável é discutível, conforme De Smet, (1997, p. 225-244). Em outro texto de Rudawski, encontramos a afirmação de que "[s]ua noção de matéria espiritual pode ter sido influenciada pelos Elementos de Teologia de Proclo" (RUDAWSKI, 1998, p. 175). Essa é a posição com a qual tendemos mais a concordar.

${ }^{16}$ Conforme o aprendizado, a ciência da matéria e da forma precede a ciência da Vontade, que precede a ciência da Essência Primeira. Mas, conforme o ser, é o inverso. (F.V., I,7)

${ }^{17}$ Outras designaçôes utilizadas são Uno, Autor Primeiro (diversas vezes, ao longo do texto), Deus (p. ex. $F V$., III, 2 e IV, 20) e também Doador da Bondade (F.V., III, 47 e IV, 9), deitatis (F.V., III, 49) e Bem. Esse Uno/Essência Primeira é qualificado da seguinte maneira: Altíssimo, Elevado, Santo, Excelso, de Excelso Nome, Eterno, Sublime (F.V.,V, 25) e, uma única vez "doador da forma” (F.V., V, 42).
} 
notar as três tradiçóes que, num primeiro momento, estarão presentes em suas ideias, ainda que se manifestem de modo diferente e em momentos distintos de sua estrutura. A primeira delas, representada aqui pela designação Essência Primeira, sugere uma linguagem aristotélica; a segunda, expressa pelo termo Uno, manifesta sua adesão ao modelo neoplatônico de processão/emanação; e a terceira é a filiação religiosa, representada aqui pelos adjetivos Altíssimo, Eterno, Santo e, principalmente, pelo "de excelso nome", uma das poucas alusóes contidas nessa obra que podem vir a indicar sua filiação religiosa específica, mesmo que não muito precisamente, já que essa expressão não é exclusivamente judaica, sendo também empregada no Cristianismo.

Esse Uno/Essência Primeira não cria diretamente os seres, e isso se refere especialmente aos seres corpóreos: "A ação do primeiro Autor é criar algo do nada. A substância que sustenta os predicamentos é composta a partir de seus simples. Logo, não é criada do nada" (F.V., III, 3 prova 16). Note-se que seu argumento aqui para advogar a necessidade de intermediários é exatamente a ideia da criação ex nibilo. A Criação, por assim dizer, é obra de uma cadeia de intermediários, em cujo extremo superior se encontra a Vontade. Ao contrário do que poderíamos esperar, no extremo inferior dos seres não se encontra a matéria corpórea (bylé), mas a última forma que nada mais produz de si, ou seja, as próprias categorias ${ }^{18}$ ou os "[...] predicamentos que são o limite da geraçáo" (F.V.,V, 28). Nesse sentido, a cadeia de seres criados estende-se desde a matéria primeira até a última forma:

Proponho-te uma regra geral para alcançar o conhecimento da matéria e da forma. Imagina, pela ordem, aquilo que existe, isto é, aquilo que sustenta os outros e o que é sustentado por outros e toma-os como dois extremos: um inferior e um superior. $\mathrm{O}$ que está no extremo superior contém tudo, sendo a matéria universal como matéria que sustenta; e aquele que está no inferior é a forma sensível, sendo somente forma sustentada. (F. $V$., II, 1).

A causa para a incapacidade da última forma sustentada em atingir novamente a matéria e ser capaz de gerar outro nível de seres é a quantidade:

Todo autor, à exceção do Autor Primeiro, necessita para sua obra de um substrato que seja suscetível de sua ação. Mas, sob esta substância não há substância que seja capaz de receber sua ação, porque é o último ser e seu

\footnotetext{
${ }^{18}$ Pelo fato de dispormos do texto em latim, o termo usado é predicamento, mas este se refere às categorias aristotélicas.
} 
limite inferior, e é como um centro para as demais substâncias inteligíveis ${ }^{19}$. E também porque a quantidade que circunscreve esta substância é a causa que a impede de agir. (F. V., II, 9).

A razão lógica pela qual a existência de um intermediário entre Deus e o universo criado é necessária é precisamente o fato de que há uma distinção radical entre eles. Seguindo aqui o imperativo judaico da dessemelhança radical entre Deus e a Criação, Gabirol afirma que essa dessemelhança existe em virtude de Deus ser infinito, ilimitado e absolutamente Uno, uma vez que não admite em si qualquer diversidade, enquanto tudo o que é criado é finito, delimitado e contém em si a diversidade, por ser composto por dois princípios opostos: matéria e forma. A Vontade é então essa intermediária entre eles e a criadora dos seres, pela uniáo dos dois princípios componentes de toda a criaçáo:

É próprio da Majestade produzir a perfeição; criar o que sustenta e o sustentado é mais perfeito que criar somente o que sustenta ou somente o sustentado. E também, posto que o Uno Criador não é nem o que sustenta nem sustentado, deduz-se que o múltiplo criado seja sustentáculo e o sustentado, pois se fosse só o sustentáculo ou só o sustentado, seria somente um e desapareceria a diversidade. Além disso, como o Autor primeiro, Sublime e Santo, é suficiente e perfeito, deduz-se que o criado paciente seja insuficiente e imperfeito, e que o sustentáculo necessite do sustentado e o sustentado do sustentáculo e que nenhum deles seja perfeito a não ser pelo outro. E também, posto que foi preciso que fosse criado um ser paciente em oposição ao ser agente e o ser agente não é finito nem delimitado, coube ao ser paciente ser finito e delimitado. E porque é delimitado deve haver uma certa determinação, porque para tudo o que é descrito deve haver descrição; e para toda descrição um descrito. Em sendo assim, deve haver uma matéria que sustente e uma forma que seja sustentada. Além disso, a diversidade que existe entre a matéria e a forma significa que existe a Vontade, à qual convém fazer uma coisa e sua oposta. E também, como foi preciso que cada um deles, o que sustenta e o que é sustentado, fossem finitos, convém que o sustentáculo seja delimitado por um não-sustentáculo e que o nãosustentáculo por um sustentáculo. E mais, dado que é preciso que o criado paciente seja dual, é preciso, pois, que um exista em si e que o outro não exista em si e o que existe em si seja o suporte e o que náo existe em si seja o sustentado; não seria possível que os dois não existissem em si, pois seria então necessário um terceiro ser para sustentá-los. (F.V., V, 25).

${ }^{19}$ Aparentemente, imagina como as esferas. 
Admitindo o argumento de que qualquer intermediário deve necessariamente manter algo em comum com os dois extremos para os quais é intermediário, a Vontade assume assim um duplo status. Por um lado, é una com Deus/Essência Primeira, enquanto propriedade criadora: "A Essência Primeira e santa, ela mesma e sua propriedade formam uma unidade sem distinção" (F.V., V, 42). Por outro lado, a Vontade e a Essência contêm em si mesmas já o princípio da diversidade, quer dizer, contêm em si ambas, a matéria e a forma, ainda que unidas e não separadas em ato. Portanto, este é o ponto em comum que a Vontade mantém com o criado.

Dado que todos os seres são compostos de matéria e de forma, a função da Vontade é justamente criar o primeiro ser através da Matéria e da Forma primeiras, as quais, por sua vez, se desdobrarão em diferentes níveis de sutileza e densidade e virão a formar tudo aquilo que existe. Ora, entendese que, como a Vontade, enquanto propriedade unida à essência de Deus, é aquela que cria o que antes náo existia, pode-se caracterizar propriamente o surgimento da matéria e da forma primeiras como criaçáo de Deus a partir do nada. Ao menos, uma criação a partir de nada extrínseco a ele, ou seja, nada que não seja a sua própria Sabedoria - na qual tudo o que existe estava antes ${ }^{20}$ prefigurado, de modo simples e unido, de um modo que não podemos compreender - e de Sua Vontade, enquanto propriedade criadora. Munk entende que, a rigor, a criação mesma se aplicaria somente à matéria e forma primeiras. Todavia, o próprio Gabirol afirma, no Fons Vitae, que a criação pode ser aplicada também às substâncias simples: "Diz-se também da matéria primeira, da forma primeira, e em geral de todas as substâncias simples, que seu ser não tem causa além de Deus que as criou" (F.V., V, 24).

Por outro lado, a questão se torna mais complicada, transformando-se em um problema, aparentemente não solucionado em sua obra, quando Ibn Gabirol se afasta da formulaçáo da questão enquanto causa de todos os seres e parte para apontar a presença da Vontade em todos os seres: "A Vontade tudo é e nela tudo está" $(F . V ., \mathrm{V}, 17)$. Essa proposição, bem como as consequências que dela decorrem, provavelmente conduziu à interpretaçáo do autor enquanto panteísta. E Gabirol explica como acontece essa presença: "A Vontade, depois que criou a matéria e a forma, uniu-se a elas como se une a alma ao corpo e se difundiu por elas e náo se separou delas, penetrando do mais alto ao extremo inferior" (F.V., V, 36). Desse modo, a continuidade da ação da Vontade nos seres e sua união com eles sugere um sistema clássico de emanaçốes, no qual a

${ }^{20} \mathrm{O}$ termo antes aqui se refere à ordem e não ao tempo, visto que a criação ocorre fora do tempo. 
dessemelhança radical entre Deus e mundo não é reforçada, e se distancia da criação a partir do nada.

Quanto à matéria e à forma primeiras e universais, Ibn Gabirol enfatiza que não é possível defini-las, porque não há qualquer gênero incidindo sobre elas. É possível somente oferecer uma descrição por meio de suas propriedades contrárias, isto é, como aquilo que sustenta e aquilo que é sustentado: "A matéria sustenta e a forma é sustentada; a matéria é oculta e a forma manifesta; a matéria adquire a perfeição pela forma e a forma completa a essência da matéria; a matéria é a delimitada e a forma é a delimitante; a matéria é separada e a forma é aquilo que separa" $(F . V ., \mathrm{V}, 23)$. Um pouco antes, no texto, assim tinha descrito as estruturas complementares:

A definição não é possível; pois não há incidindo sobre elas gênero algum que possa servir de princípio para sua definição. Mas é possível fazer uma descrição, em virtude das propriedades que as acompanham. Assim, a descrição da matéria primeira, extraída de suas propriedades é a seguinte: é uma substância que existe por si, que suporta a diversidade, e que é una em número. Pode-se ainda descrevê-la do seguinte modo: ela é a substância apta a receber todas as formas. A descrição da forma universal seria a seguinte: ela é a substância que constitui a essência de todas as formas. Pode também ser descrita como sabedoria perfeita e luz puríssima. (FV., V, 22).

Em verdade, para o autor, o gênero mais geral (genus generalissimum) não é o ser, mas a matéria universal; do mesmo modo, a forma primeira é diferença, porquanto é a própria unidade, princípio de delimitação do ser, concebido este último aqui sempre como substância. Por conseguinte, a forma primeira é a própria unidade $e$ a própria substancialidade:

Dado que aceitas que o gênero mais geral, isto é, a matéria primeira, é substância una pelo número, poderíamos dizer que a substancialidade e a unidade são sua forma. Um indício disso é que por ser una, difere das demais; a diferença é forma, logo, a unidade é forma, é o que recebe a substancialidade e a unidade, e é a coisa que se denomina propriamente una e substância. (F.V., V, 8).

Essa concepção nos conduz à discussão acerca da unidade. Por um lado, Gabirol afirma que a forma primeira é a forma da unidade. Por dedução lógica, isso nos levaria a crermos que a matéria em si mesma não possuiria unidade, adquirindo-a somente após receber a forma. Todavia, o autor insiste 
diversas vezes na unidade da matéria, conforme exposto em citação acima. Chegamos então ou a uma contradição ou inconsistência, conforme alguns estudiosos insistem em ver em Gabirol, ou à conclusão - que nos parece a mais acertada, pela leitura cuidadosa do texto - de que não se trata aqui da mesma unidade ou, ao menos, o termo unidade não é aplicado do mesmo modo.

O termo unidade, assim como seu qualificativo uno/una, é utilizado de diversas maneiras diferentes, no decorrer do texto do Fons Vitae: em primeiro lugar, é atribuído a Deus. Deus/Essência Primeira é Uno em si mesmo, e é O Uno absoluto, sem qualquer diversidade ou oposição; Sua Vontade é una também, posto que dela procede o princípio da unidade agente no mundo; além disso, a Vontade e a Essência Primeira não formam propriamente uma dualidade, uma vez que, como já referimos, a Vontade, enquanto propriedade, é una com a Essência Primeira. De fato, como qualificativo, ou de uma perspectiva lógico-linguística, podemos diferenciar aqui já três modos de atribuir a unidade (Deus/Uno; Vontade como origem da unidade; e unidade entre Deus e a Vontade) e, de certa maneira, de uma perspectiva ontológica, a partir dos efeitos, podemos explicar como se tivéssemos a unidade em dois diferentes níveis - Deus/Essência como Uno absoluto e Vontade/Propriedade como unidade agente - que, em verdade, formam um todo único, porquanto a segunda é propriedade inseparável da primeira.

A forma é também princípio da unidade, porque princípio de delimitação, diferenciação e individualização, já que a diversidade e multiplicidade procedem necessária e somente da unidade, desde o primeiro ser criado até os particulares corpóreos, tendo em vista que "[...] a forma da quantidade se resolve no ponto e na unidade" (F.V., II, 8). Por sua vez, a Inteligência, é unidade enquanto primeiro ser criado. Esta pode ser considerada também princípio de unidade, porque é ela quem transmite aos demais níveis subsequentes a forma da unidade recomposta entre matéria e forma - ou a própria forma primeira universal (unidade e substancialidade), que é forma da inteligência, porque esta não possui forma que lhe seja particular. Portanto, temos várias situaçóes em que o termo unidade ou o qualificativo Uno/Una é invocado, mas em funções lógicas ou níveis ontológicos extremamente diferenciados.

Assim, no plano do universo criado, ou seja, no plano da separação entre forma e matéria, estamos já no nível da dualidade efetiva que é reunida - por ação da Vontade, ou "unidade primeira agente" - para dar origem ao primeiro ser, a inteligência, cuja forma primeira é a "unidade que a segue", 
isto é, estamos na unidade recomposta a partir da dualidade, no dois que se torna um. Por conseguinte, esses níveis, sendo um deles o do ser criado e o outro além da criação, náo podem jamais ser confundidos. $\mathrm{O}$ termo unidade recai aqui num problema semelhante ao enfrentado pela teologia em geral enquanto discurso sobre Deus - e na sua consequente prática de atribuição de características do criado para referência ao incriado ${ }^{21}$. Nesse sentido, o empréstimo do termo matemático não quer dizer a atribuição direta de seu significado àquilo que é denominado unidade absoluta, quer dizer, àquela que é unidade por si e não pela reunião de dois princípios (ou funçôes) opostos.

D. - Por que há matéria e forma?

M. - Pela Essência Primeira e sua propriedade. E também porque o dois está situado abaixo do um e é a prova do um. Se o criado fosse um, não haveria aqui diferença, pois a diferença não está senão debaixo do um. Além disso, como o ser não tem forma, convém que o ser possua uma forma. Como o ser deve ser finito em si, convém que seja limitado por uma forma, pois é a forma que retém a coisa. E também, como a unidade primeira agente não possui hylé, é preciso que a unidade que a segue seja composta de hylé; com isso, recebe a união e se converte em dois, quer dizer, uma hylé substrato e uma unidade sustentada. Como a unidade primeira é agente e se basta em si mesma, é preciso que a unidade que a segue tenha necessidade de algo que a sustente, e por isso é preciso que exista esta hylé que a sustente e por essa razão torna-se uma dualidade. $(F . V ., \mathrm{V}, 23)$.

Logo, temos até aqui a unidade absoluta, perfeita e verdadeira (Deus), a unidade primeira agente (Vontade), a unidade seguinte (Forma Primeira) e a unidade criada (Inteligência).

Agora te darei um breve resumo do conhecimento da quantidade, e que juntes isso com o que há de seguir. Digo, pois, que a forma existente na matéria, que conduz a essência de todas as coisas à perfeição e pela qual é feito tudo o que existe, é a unidade procedente da primeira unidade que a criou, porque a primeira unidade, que é unidade para si mesma, foi criadora de outra unidade que se situa sob ela. Dado que esta unidade foi criada pela primeira, verdadeira unidade, que não tem princípio nem fim, nem mudança nem diversidade, foi necessário que a unidade criada por ela tivesse princípio e fim e que lhe sobreviesse a mudança e a diversidade, fazendo-se por isso dessemelhante à unidade perfeita que a criou. E porque, segundo o que foi dito, esta unidade é oposta à unidade perfeita verdadeira

${ }^{21}$ Que Maimônides, por exemplo, explica ser possível somente se entendido como analogia ou por homonímia. 
e lhe acomete a multiplicidade, a diversidade e a mudança, foi preciso que fosse divisível, possuindo vários graus, e que quanto mais próxima fosse a unidade à unidade primeira verdadeira a unidade mais una e mais simples fosse a matéria formada por ela. E, ao contrário, quanto mais distante estivesse da unidade primeira, mais múltipla e composta fosse. Por isso, a unidade que constitui a matéria da inteligência é una, simples, indivisível, não multiplicável essencialmente, ainda que possa ser divisível, acidentalmente. Essa unidade é a mais simples e mais una entre as que constituem as demais substâncias e isto porque está situada no extremo superior, vizinha à unidade primeira que a fez. Por isso, a substância da inteligência compreende todas as coisas pela unidade de sua essência que a constitui, porque esta unidade compreende todas as unidades que constituem as essências de todas as coisas. Isto ocorre porque as essências das unidades que subsistem nas partes da matéria - digo unidades, ou seja, as formas de todos os gêneros e todas as espécies e indivíduos - possuem o ser e a existência na essência da unidade primeira, porque todas as unidades múltiplas procedem da primeira unidade criada e a primeira unidade criada faz subsistir suas essências, porque as essências das unidades múltiplas começaram a ser a partir da essência de uma única unidade. Por isso, as formas de todas as coisas possuem o ser na forma da inteligência, nela subsistem e estão ligadas a ela; e a forma da inteligência é aquela que as sustenta e une, porque sua unidade simples é a que reúne por si todas as unidades, e as formas de todas as coisas não são mais do que unidades multiplicadas. (F. V., II, 20).

A questáo do tratamento conferido por Gabirol à unidade gerou polêmica entre os estudiosos. Numa tentativa, no mínimo, pouco ortodoxa de identificar as fontes do pensamento de Ibn Gabirol, C. K. Mathis II chegou a apresentar uma possível conexão com a metafísica de Jâmblico. Mathis enxerga, através das diferenças de linguagem, estruturas paralelas entre os sistemas metafísicos expostos por esses autores, dado que "[...] ambos os autores estabelecem um primeiro princípio quiescente seguido por um segundo princípio ativo, o qual engendra um terceiro par produtivo de uma hipóstase que é noética" (MATHIS, 1992, p. 62). Ora, tanto Jâmblico quanto Proclo defendem a existência de um intermediário entre um primeiro princípio inefável e o restante do inteligível. A nosso ver, o que temos aqui pode também derivar de uma fonte platônica comum, já que, no Parmênides ${ }^{22}$, Platão se refere igualmente a três momentos que consistiriam em três unidades

${ }^{22}$ Disponível no mundo islâmico, ao menos sob a forma de um resumo de Galeno. Cf. BADAWI, 1897, p. 36. 
distintas. Nesse sentido, ambos os autores neoplatônicos, Proclo e Jâmblico, assim como Ibn Gabirol, poderiam ter em comum nada além de sua notória (e assumida) filiação platônica. Outra possibilidade forte é que a fonte de Ibn Gabirol tenha sido o próprio Proclo, o que parece muito mais plausível, ao considerarmos os textos acessíveis na época.

Quanto à questão da unidade da matéria, o significado da atribuição do termo unidade parece ser um pouco diferente. Apesar de Gabirol afirmar que existem diversos tipos de matéria, mesmo se nos restringirmos à matéria corpórea ${ }^{23}$, afirma também que esta é una por toda a sequência de seres. De que modo pode ser isso? Isso ocorre porque, para Gabirol, a matéria é contínua, existindo do mais alto até o limite último da criaçâo. Esse qualificativo una refere-se então a tal continuidade, uma vez que, apesar de haver diferenças em termos de densidade, não há diferença essencial entre as diversas partes da matéria, mas essa diferença provém exclusivamente da forma. Essa continuidade decorre da estrutura mesma, essencialmente dinâmica, de sua metafísica que não admite funções estáticas. $\mathrm{O}$ processo de surgimento dos seres se dá de maneira contínua sem rupturas ou diferenças essenciais entre o que poderíamos denominar mundo espiritual e mundo corpóreo. É uma cadeia contínua de matérias e formas que interagem de modo dialético, descendendo até dar origem ao ser mais inferior.

D. - Posto que notei que aquilo que é matéria para a substância inferior, é forma para o superior, fez-se evidente para mim que todos os substratos, ainda que em algum sentido sejam matérias substratos, porque a substância mais sutil é substrato para a mais densa, todas são formas sustentadas na matéria primeira. E aprendi que em tudo há necessidade de uma matéria que as sustente a todas, pois, são finitas e estáo sujeitas a um único limite; logo, faz-se necessário afirmar que há uma matéria primeira universal que a todas elas sustenta, e que esta é a matéria primeira universal, objeto de nossa investigação. Por isso, tornou-se evidente para mim que a diversidade que há entre as substâncias não provém da matéria, mas da forma, porque as formas são muitas, enquanto a matéria é una. (F.V., IV, 9).

Em consequência, na perspectiva ascendente, algo que assume a função de matéria em um determinado nível assume função de forma para o nível seguinte. E é aquilo que é matéria para o inferior que será a forma para o superior, porque o mais oculto é sempre mais elevado que o mais manifesto e a

23 "Matéria particular artificial, matéria particular natural, matéria universal natural que recebe a geração e matéria celeste” (F.V., I, 17). 
forma corpórea é a mais manifesta de todas as coisas. Por conseguinte, a matéria, ao ser mais oculta, é mais sutil do que a forma. E é esse caráter de continuidade que confere o caráter de unidade à matéria, embora esta em si mesma não possua a forma da unidade, uma vez que não possui forma em absoluto.

$\mathrm{O}$ processo de surgimento dos seres a partir da unidade primeira ocorre através de unidades, portanto, Gabirol não vê aqui grandes problemas. A unidade/continuidade da matéria favorece seu modelo metafísico, porque segue fluindo - como a água - desde sua origem próxima a Deus - ou desde a fonte onde é límpida e clara - e vai se adensando, na medida do surgimento dos novos seres - onde se estanca - e assim sucessivamente, até que se torne a nossos sentidos corpórea, densa e grosseira:

Eis aqui um exemplo do que acabo de dizer sobre a simplicidade da substância, desde onde começa até a natureza, e da corporeidade da substância desde a natureza até o último centro. É como a água que corre e se precipita, correndo de um caudal a outro que, no princípio é leve e límpida, adensa-se lentamente quando estancada e torna-se turva. O mesmo ocorre com o chumbo quando é extraído do forno, em parte brilhante e translúcido e em parte ao contrário. Da mesma maneira, podemos ver claramente a diversidade de unidades na matéria que as sustenta, pois vemos as partes do fogo extremamente unidas, simples e iguais, de maneira que sua forma parece una, sem multiplicidade. Mas as partes do ar e da água, encontramo-las mais diversas e separadas, de maneira que suas partes são mais manifestas. Este é um resumo desta doutrina, quer dizer, de que a quantidade que subsiste na substância é formada pela conjunção de unidades que multiplicam e por isso foi dito que a composiçấo do mundo provém do delineamento dos números e das letras no ar. (F. V., II, 21).

Conforme já apontamos, da matéria e da forma primeiras procede o primeiro ser propriamente dito, ou a primeira substância, a Inteligência, que inicia a série das substâncias simples e espirituais. A matéria primeira universal e a forma primeira universal são as próprias componentes da Inteligência, e esta é aquela que reúne todas as formas e as apreende. Menos capaz que apreender do que a Inteligência, e ser seguinte procedente da primeira substância simples, é a Alma - concebida aqui em seus três níveis: racional, animal e vegetativo. Segue-se a esta, e defluída dela, a Natureza. Mas a estrutura gabiroliana do ser não se encerra aí, visto que com o termo Natureza Gabirol não pretende significar o conjunto das substâncias corpóreas particulares. Entendida ainda como substância espiritual pura, a Natureza dá origem, a seguir, a uma outra 
substância também considerada espiritual, aquela à qual nos referimos no início deste texto: a substância que sustenta a corporeidade do mundo.

A substância que sustenta a corporeidade do mundo não é o corpo sensível e particular; este é a matéria corpórea para o qual são formas a figura, a cor e, segundo o autor, os demais acidentes. Como o próprio nome já indica, é aquela para a qual a própria corporeidade em si é forma e possui uma matéria oculta que a sustenta. Caso seja lida de um modo mais aristotélico, diríamos que pode ser compreendida como um universal para a substância corpórea; se lida a partir de uma chave neoplatônica do tipo plotiniano, talvez possa ser entendida como atuando de modo similar à alma do mundo ${ }^{24}$, no sentido de que é uma substância simples e, portanto, incorpórea, de onde derivam as substâncias corpóreas:

Posto que o mundo é uma essência corpórea, assim como o corpo é essência dotada de figura e cor, e totalmente formada pelas formas das quais antes falamos, é necessário, por isso, que o corpo seja a matéria das formas que nele se sustentam, a saber, que são a figura as cores e demais acidentes, e que estas sejam suas formas. Da mesma maneira, é necessário que aqui exista algo que seja matéria da corporeidade e algo para o qual a corporeidade seja forma. Logo, a relação da corporeidade com a matéria que a sustenta será como a relação entre a forma universal que designávamos, isto é, figura e cor, com a corporeidade que as sustenta. Deve, pois, haver aqui uma matéria não sensível que sustente a forma do corpo. (F. $V$., II, 1).

Seguindo mais uma vez o modelo dialético de Ibn Gabirol, no qual aquilo que é matéria para o superior deve ser forma para algo que lhe seja inferior, fica claro que, se a corporeidade em si é matéria para as formas mais manifestas que se sustentam no corpo (figura, cor etc.), esta deve, necessariamente, ser uma forma mais sutil para uma matéria oculta por trás dela. Assim, será nessa substância que encontraremos a passagem do espiritual ao corpóreo, ou seja, a mediação necessária entre as substâncias espirituais, sutis, inteligíveis e simples e as substâncias corpóreas, densas, sensíveis e compostas pelos quatro elementos. Esta é uma substância de intermediação, porque sua matéria é espiritual e sutil, sendo aquilo que compartilha com as demais substâncias simples, porém, a sua forma é a própria corporeidade que, no nível seguinte, funcionará como a matéria corpórea que recebe as formas sensíveis. Ou, pela via inversa:

${ }^{24}$ Este termo não é utilizado por Ibn Gabirol, tal como aparece em diversos outros neoplatônicos medievais, inclusive Maimônides. 
E, de acordo com isso, a corporeidade do mundo, que é matéria manifesta que sustenta as formas que nela estão sustentadas, deve ser forma sustentada na matéria oculta da qual tratamos. E, segundo esta consideração, também esta matéria será forma para aquilo que a segue, até que cheguemos à matéria primeira que tudo contém. (F. V., II, 1).

Para Ibn Gabirol, tudo o que existe pode ser distribuído de acordo com as quatro questôes fundamentais - an est, quid est, qualis est e quare est. E estas perguntas estão intimamente relacionadas à questão do número. Desse modo, Deus/Essência Primeira figura no topo da lista a como verdadeira unidade, perfeita e absoluta, porquanto é aquilo ao qual só se pode perguntar se é, mas nada além pode ser dito a respeito. O segundo nível, o da inteligência, cai sob o número dois, porque se podem perguntar duas coisas: se é e o que é. Isso acontece por ser formado pelas duas essências, matéria e forma, e para o qual a matéria é gênero, conforme já mencionamos, e a forma é diferença. A terceira pergunta, de que natureza é, é aplicável, conforme Ibn Gabirol, somente a partir do nível da alma, pois é forma, de algum modo adicional, sustentada em algo que já possui um gênero e uma diferença, quer dizer, a Inteligência. À Natureza e a tudo o que por ela é engendrado corresponde o número quatro, pela ordem já descrita acima e por ser aplicável a quarta pergunta. Assim, a cada acréscimo de forma corresponde um nível e um número.

M. - Nesse capítulo, fornecer-te-ei um princípio geral suficiente que te servirá de regra. Afirmo, portanto, que o ser, desde sua extremidade superior até sua extremidade inferior se distingue em quatro graus, a saber: se é, o que é, de que natureza é e porque é. Dentre eles, o mais nobre é aquilo ao qual se pergunta somente se é, e não o que é, nem de que natureza é nem porque é, como o verdadeiro Uno, Elevado e Santo. Abaixo dele está aquilo ao qual se pergunta o que é, mas não, de que natureza é nem por que $e ́$, como a inteligência. Sob ela está aquilo ao qual se pergunta o que é e de que natureza é, mas não por que é, como a Alma. E mais abaixo ainda está aquilo ao qual se pergunta o que é, de que natureza é e porque é, como a natureza e tudo o que é engendrado por ela. Cada um deles está disposto de acordo com a ordem do número.

D. - Como assim?

M. - A pergunta "se é" ocupa o lugar do (número) um, pois ele é somente ser, a pergunta "o que é" assemelha-se ao dois, pois é composta de duas coisas: o gênero e a diferença; a pergunta "de que natureza é", é semelhante ao três, pois é sustentada naquilo que possui um "o que é" e se relaciona com ele; e a 
pergunta "porque é" assemelha-se ao número quatro, pois acrescenta-se ao "de que natureza é", ao "que é" e ao "se é", que são três. (F.V.,V, 24).

Já à Vontade, à matéria e à forma as três perguntas não se aplicam, uma vez que a resposta à questão $o$ que é pressupóe a concorrência de dois elementos que não estão disponíveis em cada uma delas separadamente. Dessa maneira, entende-se o que antes foi exposto: o termo unidade aplicado a Deus - unidade verdadeira; o termo unidade aplicado à Vontade criadora - unidade agente, enquanto causa de tudo o que existe; o termo unidade aplicado à forma primeira - unidade que se segue como princípio da diversidade; e unidade aplicada à matéria - em virtude de sua continuidade. O número dois é aqui atribuído à inteligência em virtude de sua composição dual que permite algum tipo de definição (gênero e diferença), mas, enquanto primeiro ser propriamente dito, é o máximo da unidade possível no mundo criado, em virtude da união perfeita entre matéria e forma realizada pela Vontade, por sua proximidade da fonte da unidade.

M. - A Essência Primeira e santa, ela mesma e sua propriedade formam uma unidade sem distinção, mas a matéria e a forma são distintas, porque são o princípio da ação da unidade, constituem aquilo que primeiro a segue, sem intermediário. E considera isso na multiplicidade que sobrevém à forma, à medida que a substância se afasta da origem da unidade. A prova é a seguinte: a matéria da inteligência está mais unida à forma e é de maior simplicidade que a matéria da alma; e a matéria da alma, mais que a matéria da natureza, até que se chegue ao corpo, no qual se encontra a maior multiplicidade e diversidade. $\mathrm{O}$ mesmo se há de dizer das gradaçóes corporais, pois o corpo do céu é mais unido e simples que o dos elementos, e dentre estes elementos, o que mais elevado é mais unido e simples que o inferior. Isso também é prova de que a matéria universal e a forma universal seguem a unidade, com criaçáo imediata, enquanto que na natureza, a matéria recebe a forma da unidade segundo a diversidade de sua percepção, pois uma sustenta e a outra é sustentada. (F.V., V, 42).

Vale ressaltar ainda que Ibn Gabirol frisa que, embora tenha descrito a forma como sendo a própria unidade e substancialidade, pelo fato de que ser ela quem produz as coisas, conduzindo-as à existência por conferir-lhes sua essência, essa descrição não pode ser tomada de modo absoluto. Isso se dá em virtude da dependência necessária que a forma mantém para com a Vontade, 
da qual recebe a unidade. E, conforme Gabirol, essa recepção da unidade pela forma ocorre por impressão da Vontade:

M. - Não vês que a existência da essência de todas as coisas não se dá senáo a partir da matéria e da forma, e a existência da matéria e da forma a partir da Vontade, porque é ela que as produz, que as une e as retém? Por isso, ainda que digamos que a forma retém a matéria, dizemos de maneira imprópria, porque a forma recebe da Vontade a faculdade pela qual retém a matéria; também podemos dizer que a forma é a impressão da unidade e a faculdade de reter é da unidade; mas a Vontade retém a matéria através da forma e por isso se diz que a forma retém a matéria, porque a forma é a intermediária entre a matéria e a Vontade; logo, ela adquire da Vontade e dá à matéria. E porque a Vontade procede da origem primeira, esta se infunde com ela na matéria e na forma; e aquela e estas existem em tudo, e nada há sem elas. (F.V., V, 39).

A forma em si mesma é tão indigna quanto nobre; e tão nobre e indigna quanto a matéria, porque nenhuma das duas separadamente é capaz de agir por si. Toda ação, movimento e mesmo divisão acontece pela Vontade: "E a prova de que a Vontade é uma coisa distinta da forma é a indigência da forma, a qual necessita de algo que a mova, que a meça, que a divida e outras coisas mais, pelas quais se designa a Vontade, conforme antes já indicamos" (F.V., V, 42).

Ora, se a Vontade é de certo modo unida à Essência Primeira e não algo é algo distinto dela, a unidade da forma e que esta confere aos seres/ substâncias pela sua ligação com a matéria - em última análise - procede da unidade do próprio Uno em si mesmo.

Considera o limite da criação, isto é, o início da uniấo da forma com a matéria, e imagina a essência que não possui princípio ou fim, que é a essência do Criador; e imagina tudo o que existe, tanto espiritual como corporal, existindo nela, como te representas algumas idéias que existem em tua alma. Entáo verás que a virtude do Criador, Excelso e Santo, está em tudo o que existe Nele; e verás igualmente que a força e a essência das coisas superiores estão no inferior, até seu fim, isto é, até a extremidade última do repouso. De acordo com isso, imaginarás a extensão da matéria e da forma desde o mais alto até o mais baixo, numa extensão contínua. (F.V., V, 30).

Com base no exposto, se, por um lado, o modelo metafísico de Ibn Gabirol nada tem aparentemente a ver com o relato do Gênesis sobre a 
criação dos seres como tais a partir do nada, em seis dias, por outro lado, o autor consegue garantir que os maiores problemas oferecidos pelo modelo neoplatônico da processão/emanação sejam removidos. Uma vez que caracteriza a indigência da forma em si mesma, quando desprovida da ação da Vontade, Ibn Gabirol garante a criação livre, voluntária e intencional por Deus/Uno/Essência Primeira, através de sua pura Vontade - propriedade criadora - afastando qualquer tipo de necessitarismo ou criação acidental por um Uno que transborda involuntariamente, gerando hipóstases separadas. Podemos sustentar que, além disso, o autor mantém assim a presença de Deus num mundo que já existia anteriormente prefigurado em Sua Sabedoria. Isso, ao mesmo tempo em que reforça a concepção judaica da livre Vontade de um Deus criador, pode sugerir algum tipo de consubstancialidade entre Deus e a Criação. Conforme expusemos, para Gabirol, a diferença fundamental entre Deus e a Criação é que Deus é a unidade verdadeira e perfeita, sem divisóes, e toda e qualquer unidade existente no mundo é unidade por reconduçáo à unidade de dois princípios diferenciados, como podemos ver abaixo:

D. - A essência do ser universal25, é una ou múltipla?

M. - Múltipla, certamente. Mas ainda que seja múltipla e diversa concorda, no entanto, em dois, pelos quais se sustenta e possui o ser.

D. - E quais são estes dois?

M. - A matéria universal e a forma universal.

D. - De que modo tudo aquilo que é concorda nestas $\operatorname{duas}^{26}$ ?

M. - Porque elas são a raiz de tudo e a partir delas foi gerado tudo aquilo que é.

D. - E como estas duas são as raízes de tudo o que é?

M. - Porque, por natureza, a tudo precedem e também nelas tudo se resolve.

D. - De que modo nelas tudo se reduz?

M. - Porque a matéria primeira universal é mais simples que toda matéria e é fim último de toda matéria; do mesmo modo, a forma universal é mais simples que toda forma e esta forma mesma é a unificadora de todas as formas. (F. V., I, 5).

No entanto, para explicar essa diferença, temos que entender a origem da matéria e da forma. E aqui surgem algumas alternativas: a primeira delas

\footnotetext{
${ }^{25}$ Essentia esse universalis - "ser universal" refere-se a tudo aquilo que é, e não ao ser superior, absoluto, o Uno Altíssimo.

${ }^{26} \mathrm{O}$ gênero masculino utilizado para dois enquanto estava indefinido foi modificado para o feminino, a fim de concordar com o sujeito "matéria e forma universais".
} 
seria assumir que a forma é criada porque procede da Vontade, mas a matéria não seria criada, sendo, de algum modo preexistente ${ }^{27}$. Esta é uma questáo que consta do Fons Vitae formulada pelo discípulo da seguinte maneira: "Já ficou claro pelo dito anteriormente que a matéria não possui ser e a criação é aquisição de ser, de onde se deduz que a matéria não seja criada”. A isso Gabirol responde, nas palavras do mestre:

Não houve matéria sem forma nem por um único instante, e por isso não pode não ter sido criada nem que não possua ser. Mas foi criada simultaneamente à forma, porque náo possui o ser mais do que pela forma, ou seja, foi criada com a criação da forma que nela está sustentada, sem espaço nem tempo. (F.V., V, 42).

Portanto, o autor defende que a matéria é criada.

A segunda alternativa seria afirmar que tanto a matéria quanto a forma procedem da Vontade e, então, não somente esta seria causa agente da união entre os dois princípios para ao surgimento dos seres, mas também seria causa agente de sua origem separada, quer dizer, da própria separação entre matéria e forma. Teríamos aqui um problema estranho: por que razão a Vontade separaria os dois princípios para uni-los a seguir? O discípulo apresenta essa dúvida, visto que, para ele a origem da forma está explicada, mas a origem da matéria ainda permanece obscura: "Tornemos a falar do que antes nos ocupávamos, isto é, de que todas as formas, que subsistem na matéria são impressôes da sabedoria da Essência Primeira. E, supondo que isso dizemos sobre a forma, o que diríamos sobre a matéria?” Gabirol, nas palavras do mestre, explica que a matéria procede diretamente da essência enquanto a forma procede da Vontade, ou seja, de sua propriedade, concebida por ele enquanto sabedoria e unidade.

Da matéria dizemos o mesmo que da forma, isso é, que a matéria é criada pela essência e a forma pela propriedade da essência, isto é, pela sabedoria e pela unidade, ainda que a essência não seja determinada por propriedade extrínseca a ela. Esta é a diferença entre o criador e o criado, porque o

\footnotetext{
${ }^{27}$ Não há como afirmar que a teoria da preexistência da matéria seja de todo herética, no seio do judaísmo. Ressalta Maimônides: "De todo modo, caso admitíssemos a eternidade do Universo conforme a segunda das teorias que expusemos - a de Platão - de acordo com a qual os Céus também são transitórios - não nos oporíamos aos princípios fundamentais de nossa religiáo, pois esta teoria não implica na rejeição de milagres, mas admite a possibilidade" (MAIMÔNIDES, 1956, II, 25). Para a discussão da questão da preexistência da matéria nos círculos rabínicos, ver ALTMANN, 1969.
} 
Autor é a essência essencial e o que é criado se compóe de duas essências, que são a matéria e a forma. (F. V., V, 42).

Assim, a unidade que a forma confere aos seres é propriedade sua, porque conferida pela unidade agente, ou a partir da propriedade da Essência que é Una em si mesma; as formas existentes em todas as coisas procedem do que já havia prefigurado em Sua Sabedoria. Contudo, a matéria não procede da Vontade, mas da Essência mesma. Nesse sentido, a matéria traz consigo o caráter de indeterminação no seu sentido mais próprio, ou seja, de ausência de limites, que lhe vem do próprio Deus/Essência Primeira, enquanto contínua e indiferenciada em si mesma, por proceder diretamente da Essência. Nesse sentido, a matéria de Ibn Gabirol, como substrato universal, não está longe do apeiron enquanto princípio, entendido este talvez como equivalente ao estado antes da criação (tohu va bohu), referido em Gênesis 1: 2.

Nosso pensamento está habituado a entender a forma como superior à matéria e esta é uma das raízes de uma das mais sérias contradiçôes atribuídas a Ibn Gabirol. Gabirol nos explica, em seu modelo a partir da substância sensível e corpórea, que a forma corpórea é o limite inferior de todas as coisas e a matéria oculta sob ela lhe é superior. Essa mesma matéria funcionará como forma para o nível acima. Seguindo uma estrutura ascendente de formas manifestas e matérias ocultas que serão formas para o nível acima, o extremo superior da criaçáo seria precisamente a matéria primeira.

Mas Gabirol afirma que a forma sobrevém à matéria para a constituição do primeiro ser criado, a Inteligência:

D. - Se a matéria e a forma procedem da essência e da propriedade, por que se diz que a forma é acrescentada à matéria e de onde vem a ela?

M. - A forma vem do superior e a matéria a recebe do inferior porque a matéria é substrato, dado que possui o ser sob a forma e a forma está sustentada acima dela. (F. V, V, 42).

A explicação para a questão está exatamente na Vontade e no que foi anteriormente exposto acerca da indigência da forma em si mesma. Entendemos que não é a própria forma primeira que atinge a matéria primeira, mas é a Vontade que age sobre o princípio de indeterminação e então estas se tornam forma e matéria. É a Luz ou Verbo de Deus/Essência Primeira que atinge um princípio indeterminado e contínuo procedente dessa própria Essência, determinando a criação. A matéria, portanto, está abaixo da Vontade, mas 
não necessariamente abaixo da forma: "Os filósofos só chamam a matéria de possibilidade porque lhe foi possível receber a forma, isto é, ser revestida com sua luz. E esta necessidade provém somente de estar abaixo da Vontade e a Vontade acima da forma; por isso não devemos nos admirar". E continua sobre a recepção da forma pela matéria, afirmando que a matéria recebe a forma "[...] mediante a Vontade. E por isso se diz que a matéria é como o trono do Uno e que Vontade que lhe confere a forma está sentada nele e nele descansa" (F.V., V, 42). Assim, percebemos que a tríade fundamental para Ibn Gabirol parece ser composta por Deus, Vontade e Matéria, e a partir deles procedem todos os seres. Ora, esses três elementos estão também interligados de algum modo, enquanto essência, propriedade, e princípio material procedente da essência, o que igualmente faria deles, de certo modo, uma unidade, porém, essa relação não é o tema do presente artigo e este estudo demandaria uma profundidade que não cabe aqui.

MACEDO, Cecilia Cintra Cavaleiro de. Ibn Gabirol and the origin of the world: notes on the question of unity. Trans/Form/Ação, Marília, v. 35, p. 43-66, 2012. Edição Especial.

\begin{abstract}
In his work Fons Vitae, Ibn Gabirol presents a metaphysical model based on universal hylomorphism, i.e., on the presence of matter and form in all beings both corporeal and spiritual. Although considered a neoplatonic author, Ibn Gabirol does not properly present a henology, but starts from sensible and corporeal realities and then treats the more subtle ones. This article intends to invert the author's presentation, seeking to redesign his metaphysics from the first essence to the end of creation. To this end, the specific point that is analyzed (although in an incipient way) is the question of unity and its qualifier 'one', both in the attribution Ibn Gabirol makes in his ontological model and in the model's logical aspects.
\end{abstract}

KEYWORDS: One. Unity. Ibn Gabirol. Neoplatonism. Universal Hylomorphism. Matter.

\title{
REFERÊNCIAS
}

ABRAVANEL, Yehudah (LEÃO HEBREU). Diálogos de Amor. Lisboa: Imprensa NacionalCasa da Moeda, 2001.

ALTMANN, A. A note on the rabbinic doctrine of Creation. In: Studies in religious philosophy and mysticism. New York: Cornell University Press, 1969, p. 128-139.

ALTMANN, A.; STERN, S. M. Isaac Israeli, a Neoplatonic Philosopher of the early tenth century, Oxford: Clarendon Press, 1958. 
AVENCEBROLIS (IBN GABIROL) Fons vitaelex Arabico in Latinum translatum ab Iohanne Hispano et Dominico Gundissalino; ex codicis Parisinis, Amploniano, Columbino primum edidit Clemens Baeumker. Münster: Aschendorff, 1895.

BADAWI, Abdurrahman. La Transmission de la Philosophie Grecque au Monde Arabe. Paris: Librairie Philosophique J. Vrin, 1897.

BRUNNER, F. Platonisme et Aristotelisme, La critique d'Ibn Gabirol par Saint Thomas D’Aquin. Louvain: Publications Universitaires de Louvain, 1965.

DE SMET, Daniel. The Influence of the Pseudo-Empedocles on Medieval Latin Philosophy: Myth or Reality? In: Across the Mediterranean Frontiers: Trade, Politics and Religion, Agius, D. A; Netton, I.R. Turnhhout: Brepols, 1997, p. 225-244.

GUTTMANN, Julius. A filosofia do Judaísmo. São Paulo: Perspectiva, 2003.

KAUFMANN, D. Studien über Salomon ibn Gabirol. Budapest, 1899.

MAIMÔNIDES, Moses. Dalalat al-Hairin/ The Guide for the Perplexed. Tradução do original árabe por M. Friedlander. NY: Dover Publications, 1956.

MATHIS II, C. K. Parallel Structures in the Metaphysics of Iamblichus and Ibn Gabirol. In GOODMAN, L. (Org.). Neoplatonism and Jewish Thought. Studies In Neoplatonism: Ancient and Modern, vol. 7. Albany: State University of New York Press, 1992.

MUNK, Salomon. Mélanges de Philosophie Juïve et Arabe. Paris: Librairie Philosophique J. Vrin, 1927.

PROCLO. Elementi di Teologia. Int., trad. e comentario: Eva Di Stefano. Symbolon, Studi e testi di Filosofia Ântica e Medievale. Università di Catania, Firenze: La Nuova Itália, 1994.

RUDAWSKI, Tamar. Medieval Jewish Neoplatonism. In: FRANK, Daniel; LEAMAN, Oliver (Org.). History of Jewish Philosophy. London: Routledge, 2003. p. 149-187.

RUDAWSKI, Tamar. Solomon Ibn Gabirol. In: POPKIN, Richard H. The Columbia History of Western Philosophy. Columbia University Press, 1998, 173-177.

STERN, S. M. Ibn Hasday's Neoplatonist. A Neoplatonic Treatise and its Influence on Isaac Israeli and the longer Version of the Theology of Aristotle. ORIENS. Journal de la Société Internationale d'Etudes Orientales. Vol. 13-14. 1960-1961.

VILA-CHÃ, João S. J. "Leão Hebreu e o significado de sua obra” In LEÃO HEBREU, Diálogos de Amor. Apresentação João Vila-Chã; Tradução Giacinto Manupella. Coleção Pensamento Português. Lisboa: Imprensa Nacional-Casa da Moeda, 2001. p. 9-55. 